\title{
Biologically synthesized silver nanoparticles by aqueous extract of Satureja intermedia C.A. Mey and the evaluation of total phenolic and flavonoid contents and antioxidant activity
}

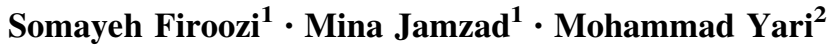

Received: 4 August 2016/ Accepted: 6 October 2016/Published online: 15 October 2016

(c) The Author(s) 2016. This article is published with open access at Springerlink.com

\begin{abstract}
Developing low cost and environmentally friendly methods for metallic nanoparticles is an increasing need. Using plants towards synthesis of nanoparticles are beneficial with the presence of bio-molecules in plants, which can act as capping/stabilizing and reducing agents. In the present attempt, we describe rapid biosynthesis of silver nanoparticles by Satureja intermedia C. A. Mey (Lamiaceae) aqueous extract. Synthesized nanoparticles were characterized by UV-Visible spectroscopy, X-ray diffraction (XRD), transmission electron microscopy (TEM) and the chemical groups in plant extract were detected by Fourier Transform Infra-Red (FT-IR) spectroscopy. The XRD study showed crystalline nature and face cubic center shape for nanoparticles. TEM study showed that the mean diameter and standard deviation for the silver nanoparticles were $29.29 \pm 28.18 \mathrm{~nm}$. Total phenolic and flavonoid contents and radical scavenging activity of the aqueous extract and SNPs/extract mixture, were also evaluated in this study. It can be concluded that the aerial parts of $S$. intermedia is a good source of phenolic compounds, a potent antioxidant and a valuable choice for bio-reduction and biosynthesis of silver nanoparticles.
\end{abstract}

Keywords Satureja intermedia - Silver nanoparticles . Phenolic compounds · Flavonoids · Radical scavenging effect

Mina Jamzad

minajamzadiau@gmail.com; m.jamzad@qodsiau.ac.ir

1 Department of Chemistry, Shahr-e-Qods Branch, Islamic Azad University, Tehran, Iran

2 Department of Chemistry, Islamshahr Branch, Islamic Azad University, P.O. Box: 33135-369, Islamshahr, Iran

\section{Introduction}

Nanotechnology is one of the most fascinating research areas in modern material science. In general, particles with a size less than $100 \mathrm{~nm}$ are referred to as nanoparticles. Entirely novel and enhanced characteristics such as size, distribution and morphology have been revealed by these particles in comparison to the larger particles of bulk material [1]. Nanoparticles are gaining importance in the fields of biology, medicine and electronics owing to their unique physical and biological properties [2]. Among the metallic nanoparticles, Silver has been enormously utilized for its diverse applications in the fields of bio-labeling, opt biosensors, polarizing filters, electrical batteries, cancer cell imaging, drug delivery systems etc. [3]. Silver has long been recognized as having an inhibitory effect toward many microorganisms [4] while it is not toxic to human cells in low concentrations [5]. The most widely used and known applications of silver and silver nanoparticles are in the medical industry; for example, in topical ointments to prevent infection of burns or open wounds and also in medical devices and implants [6].

Many techniques of synthesizing silver nanoparticles (SNPs) have been reported in the literature; and chemical reduction is the most commonly used method for the preparation of SNPs [7]. Reducing agents commonly used in chemical reduction are borohydride, citrate, ascorbate, and elemental hydrogen [8]. Most of these methods are extremely expensive and also involve the use of toxic and hazardous chemicals, which may pose potential environmental and biological risks. Since noble metal nanoparticles are widely applied to areas of human contact, there is a growing need to develop environmental friendly processes for nanoparticle synthesis that do not use toxic chemicals [9]. 
Nowadays, green synthesis of nanoparticles from plants is an utmost emerging field in nanotechnology. Previously, noble nanoparticles were synthesized by using various plant materials like: Mentha piperita [10]; Ipomoea pescaprae [11]; Ocimum sanctum [12]; Amaranthus dubius [13] etc. The exact mechanism of SNPs synthesis mediated by plant extracts is not yet fully understood. It is expected that plants with higher reducing capacity are more potent in reducing metallic ions to metallic nanoparticles [14]. Phenolic compounds are the major constituents of antioxidants of most plant species and their antioxidant activity is mainly due to their redox properties. As a result, they can act as reducing agents in neutralizing free radicals $[15,16]$ and the reduction of metallic ions to metallic nanoparticles [17].

In this study, we evaluated total phenolic and flavonoid contents in aqueous extract of Saturaja intermedia C. A. Mey (Lamiaceae). Results showed that the extract is rich of these biomolecules and the plant can be a good choice for bio-reduction processes. So we investigated biosynthesis of SNPs mediated by the aqueous extract of $S$. intermedia and found an easy and rapid procedure for this purpose. Anti-oxidant activity of the extract and the SNPs/ extract mixture, were also evaluated in this study.

\section{Experimental}

\section{Chemicals}

1, 1-Diphenyl-2-picrylhedrazyl (DPPH) and Gallic acid were prepared from Sigma-Aldrich (US). Quercetin, FolinCiocalteu reagent, Aluminum chloride, Sodium bicarbonate, Sodium acetate, Butylated hydroxyl toluene (BHT), Silver nitrate and all the solvents were purchased from Merck (Germany).

\section{Instrumental}

UV-Visible spectrophotometer (CECIL, CE 7800, UK); X-Ray diffractometer (Intel, EQUINX -3000, France); FTIR spectrophotometer (Perkin-Elmer, Spectrum100, Germany); Transmission electron microscope (TEM) ¿1GMAVP, Zeiss, Germany); Ultrasonic (Elma, S15H, Germany); Centrifuge (EBA20, Hettich, Germany).

\section{Plant material}

The aerial parts of Satureja intermedia C. A. Mey (including leaves, stems and flowers), was collected during flowering stage from Gardaneh Almas (2350-2400 m), between Astara and Ardabil, (Iran), on June 2014. Voucher specimen (No: 83139) has been deposited at the Herbarium of Research Institute of Forests and Rangelands (TARI), Tehran, Iran.

\section{Preparation of the extracts}

Dried and powdered aerial parts of Satureja intermedia $(20 \mathrm{~g})$ were soaked in de-ionized water $(200 \mathrm{~mL})$ and boiled for $10 \mathrm{~min}$. After filtration, the extract was concentrated to $1 / 3$ initial volume and then centrifuged at $4000 \mathrm{rpm}$ for $15 \mathrm{~min}$ and kept in a dark bottle at $22^{\circ} \mathrm{C}$ for further uses.

\section{Total phenolic contents}

Determination of total phenolic contents was carried out following the Folin-Ciocalteu method by Singleton and Rossi [18]. Briefly, $100 \mu \mathrm{L}$ of the extract $(20 \mathrm{mg} / \mathrm{mL})$ was mixed up with $0.75 \mathrm{~mL}$ of Folin-Ciocalteu reagent (previously diluted 10-fold with distilled water) and allowed to stand at room temperature $\left(22^{\circ} \mathrm{C}\right)$ for $5 \mathrm{~min}$. Then $0.75 \mathrm{~mL}$ of sodium bicarbonate $(60 \mathrm{mg} / \mathrm{mL})$ solution was added and mixed thoroughly. Finally, the sample was measured spectrophotometrically at $765 \mathrm{~nm}$ after $90 \mathrm{~min}$ at room temperature. The experiment was also repeated for the mixture including synthesized silver nanoparticles and the plant extract. A calibration curve was plotted for the standard solutions of Gallic acid $(0-100 \mathrm{ppm})$ with the standard curve equation $(Y=$ $\left.0.0105 X+0.0138, R^{2}=0.9955\right)$. Total phenolic contents of the samples were expressed in terms of Gallic acid equivalent ( $\mathrm{mg} / \mathrm{L}$ and or $\mathrm{mg} / \mathrm{g}$ ). Experiments were performed in triplicate and expressed as mean \pm standard deviation (SD).

\section{Total flavonoid contents}

Total flavonoid contents were determined by aluminum chloride colorimetric method which is based on the formation of a complex flavonoid-aluminum having the maximum absorption at $415 \mathrm{~nm}$ [19]. Briefly, $0.5 \mathrm{~mL}$ of the extract and the mixture including extract and silver nanoparticles $(20 \mathrm{mg} / \mathrm{mL})$ were dissolved in methanol $(1.5 \mathrm{~mL})$ separately, and then $10 \%$ aluminum chloride $(0.1 \mathrm{~mL})$ and $1.0 \mathrm{M}$ sodium acetate $(0.1 \mathrm{~mL})$ were added to the samples. Finally, distilled water $(2.8 \mathrm{~mL})$ was added, and the solutions were incubated at room temperature. After half an hour the absorbance of the reaction mixtures was measured at $415 \mathrm{~nm}$ by a UV-Visible spectrophotometer. The calibration curve was plotted by employing the same procedure for the standard solutions of quercetin (0-100 ppm) with the standard curve equation 
$\left(Y=0.0673 X+0.0051, R^{2}=0.9961\right)$. Flavonoid contents of the extract and SNPs/extract mixture were expressed in terms of quercetin equivalent $(\mathrm{mg} / \mathrm{L}$ and or $\mathrm{mg} / \mathrm{g}$ ). Experiments were performed in triplicate and expressed as mean \pm standard deviation (SD).

\section{Synthesis of silver nanoparticles}

A $100 \mathrm{~mL}$ aliquot of a $0.01 \mathrm{M}$ solution of $\mathrm{AgNO}_{3}$ was gradually added to $20 \mu \mathrm{L}$ of the aqueous extract of $S a$ tureja intermedia. The mixture was kept in an ultrasonic during the addition, and then was stirred in a magnetic stirrer $(500 \mathrm{rpm})$ at room temperature for $48 \mathrm{~h}$. Silver nanoparticles were gradually obtained during the reaction. The solution turned light yellow after $2 \mathrm{~h}$ and then a dark brown color appeared, indicating the formation of SNPs. The synthesized nanoparticles were filtered with a membrane filter paper $(0.2 \mu \mathrm{m})$ and washed by de-ionized water. Finally, SNPs were dried for one hour in an oven at $100{ }^{\circ} \mathrm{C}$ and kept at room temperature for further evaluations.

\section{DPPH radical scavenging assay}

Electron donation ability of the extract, SNPs/extract mix and BHT as a standard were measured from the bleaching of the purple-colored methanol solution of DPPH. To determine the radical scavenging ability, the method reported by Bondet et al. was used [20]. Briefly, $2.5 \mathrm{~mL}$ of DPPH solution in methanol (40 $\mu \mathrm{g} / \mathrm{mL})$ (freshly prepared), was added to $10 \mu \mathrm{L}$ of the samples. After 30 min incubation in dark, absorbance of the test tubes, were taken by a spectrophotometer at $517 \mathrm{~nm}$. The percentage of scavenged DPPH was calculated using the following equation: $\% I=100\left[\frac{A_{\mathrm{c}}-A_{\mathrm{s}}}{A_{\mathrm{c}}}\right]$, where $A_{\mathrm{c}}$ is the absorbance of control (containing all reagents except the test samples), and $A_{\mathrm{s}}$ is the absorbance of sample. Experiments were done in duplicate and the average was calculated for the absorbance of each test tube.

\section{Characterization of silver nanoparticles}

UV-Visible absorbance spectroscopy of synthesized SNPs was performed. The sample was prepared by diluting $50 \mu \mathrm{L}$ of the mixture (collected at the end of reaction) in $3 \mathrm{~mL}$ of de-ionized water. The wave length was ranged from 200 to $800 \mathrm{~nm}$ and de-ionized water was used as blank. Fourier-Transform Infra-Red (FT-IR) spectra was carried out by $\mathrm{KBr}$ pellet method to identify the possible chemical functional groups and bonds in the synthesizing medium containing the plant extract responsible for the reduction and capping SNPs. Crystalline nature of metallic silver nanoparticles was examined using an X-ray diffractometer, equipped with $\mathrm{Cu} \mathrm{K} \alpha$ radiation source using $\mathrm{Ni}$ as filter at a setting of $30 \mathrm{kV} / 30 \mathrm{~mA}$. Transmission electron microscopy (TEM) was performed for the determination of morphology, size and crystalline nature of the synthesized SNPs.

\section{Results and discussion}

Total phenolic and flavonoid contents of the aqueous extract of S. intermedia and SNPs/extract mix were evaluated (Table 1). As it is seen the plant is rich in flavonoids $(21.123 \pm 0.0698 \mathrm{mg} / \mathrm{L} ; 2.006 \pm 0.0087 \mathrm{mg} / \mathrm{g})$ and phenolic compounds $(25.289 \pm 0.0698 \mathrm{mg} / \mathrm{L} ; \quad 2.398 \pm$ $0.0028 \mathrm{mg} / \mathrm{g}$ ). Total flavonoids and phenolic compounds in silver suspension were found $(3.758 \pm 0 \mathrm{mg} / \mathrm{L} ; 0.357 \pm$ $0 \mathrm{mg} / \mathrm{g})$ and $(5.352 \pm 0.078 \mathrm{mg} / \mathrm{L} ; 0.507 \pm 0.0031 \mathrm{mg} / \mathrm{g})$, respectively. Each sample had three replicates and data were shown as mean \pm standard deviation (SD).

In the next part of our study, green synthesis of silver nanoparticles through $S$. intermedia aqueous extract was carried out. The appearance of pale yellow to dark brown coloration of the reaction mixture indicated the biosynthesis of silver nanoparticles (Fig. 1). It is well known that silver nanoparticles exhibit striking colors (light yellow to brown) due to the excitation of surface Plasmon vibrations in the particles [21].

Table 1 Total phenolic and flavonoid contents of Satureja intermedia aqueous extract and silver nanoparticles/extract mixture

\begin{tabular}{|c|c|c|c|c|}
\hline & Phenolic contents $(\mathrm{mg} / \mathrm{L})^{\mathrm{a}}$ & Phenolic contents $(\mathrm{mg} / \mathrm{g})^{\mathrm{b}}$ & Flavonoid contents $(\mathrm{mg} / \mathrm{L})^{\mathrm{c}}$ & Flavonoid contents $(\mathrm{mg} / \mathrm{g})^{\mathrm{d}}$ \\
\hline Extract & $25.289 \pm 0.0698$ & $2.398 \pm 0.0028$ & $21.123 \pm 0.0698$ & $2.006 \pm 0.0087$ \\
\hline SNPs/extract & $5.352 \pm 0.078$ & $0.507 \pm 0.0031$ & $3.758 \pm 0$ & $0.357 \pm 0$ \\
\hline
\end{tabular}

Values are expressed as mean $\pm \mathrm{SD}, \mathrm{n}=3$

a Total phenolic content in terms of Gallic acid equivalent (mg of Gallic acid/L of the extract and or SNPs/extract mixture)

b Total phenolic content in terms of Gallic acid equivalent ( $\mathrm{mg}$ of Gallic acid/g of dried plant material)

c Total flavonoid content in terms of quercetin equivalent (mg of Quercetin/L of the extract and or SNPs/extract mixture)

${ }^{\mathrm{d}}$ Total flavonoid content in terms of quercetin equivalent (mg of Quercetin/g of dried plant material) 
Fig. 1 Color changes before

(a) and after (b) biosynthesis of

SNPs by Satureja intermedia

C.A. Mey (c) aqueous extract
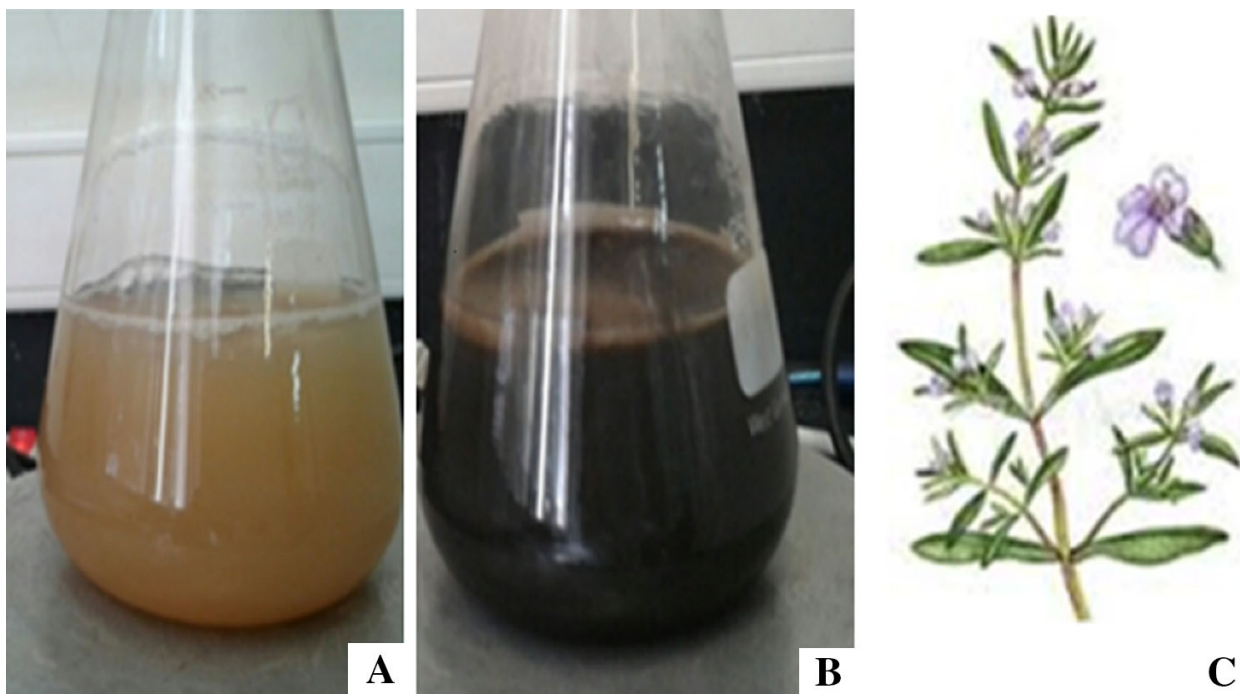

B

C
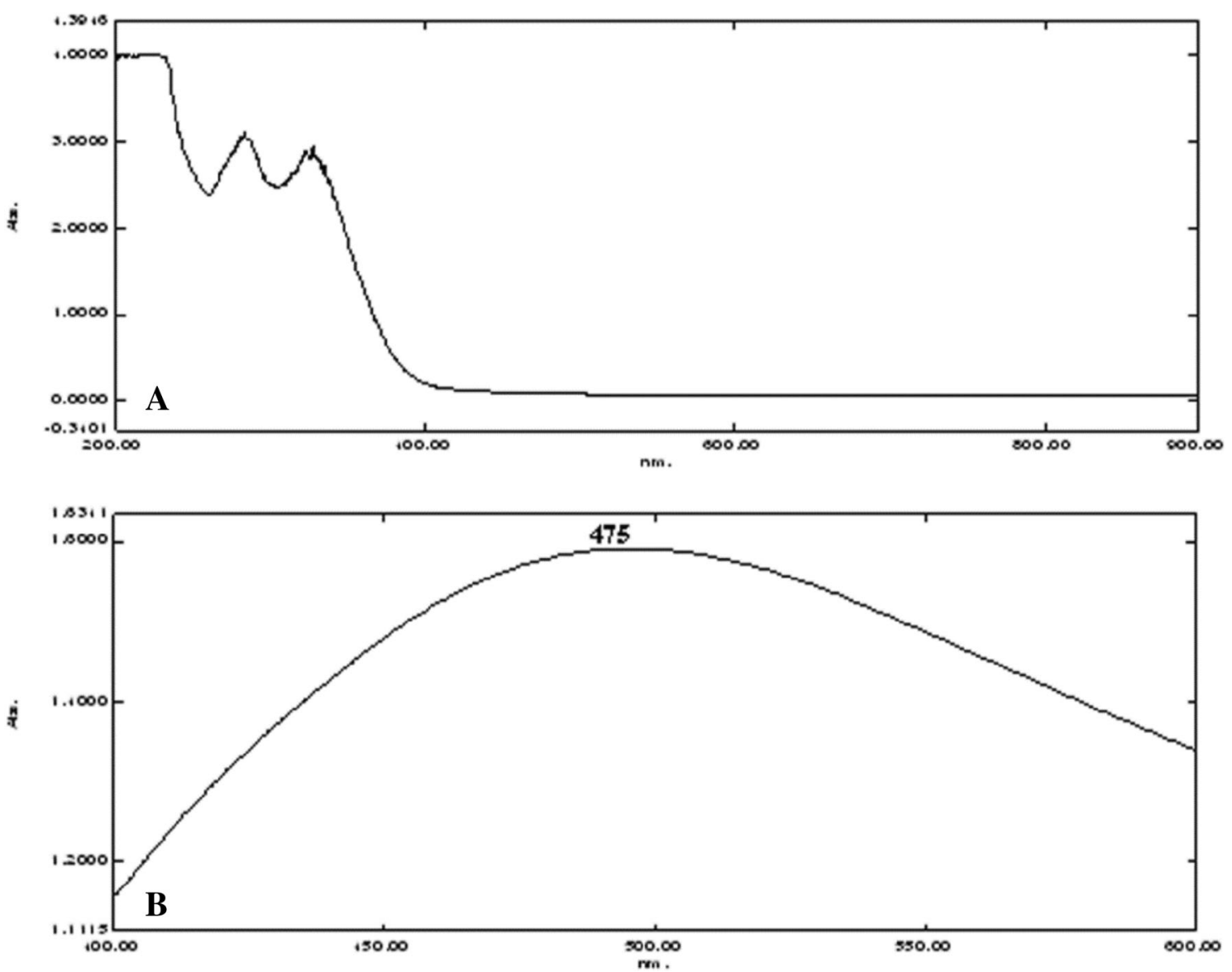

Fig. 2 UV-Vis absorption spectra of a Satureja intermedia C. A. Mey and b SNPs/Satureja intermedia extract mixture 


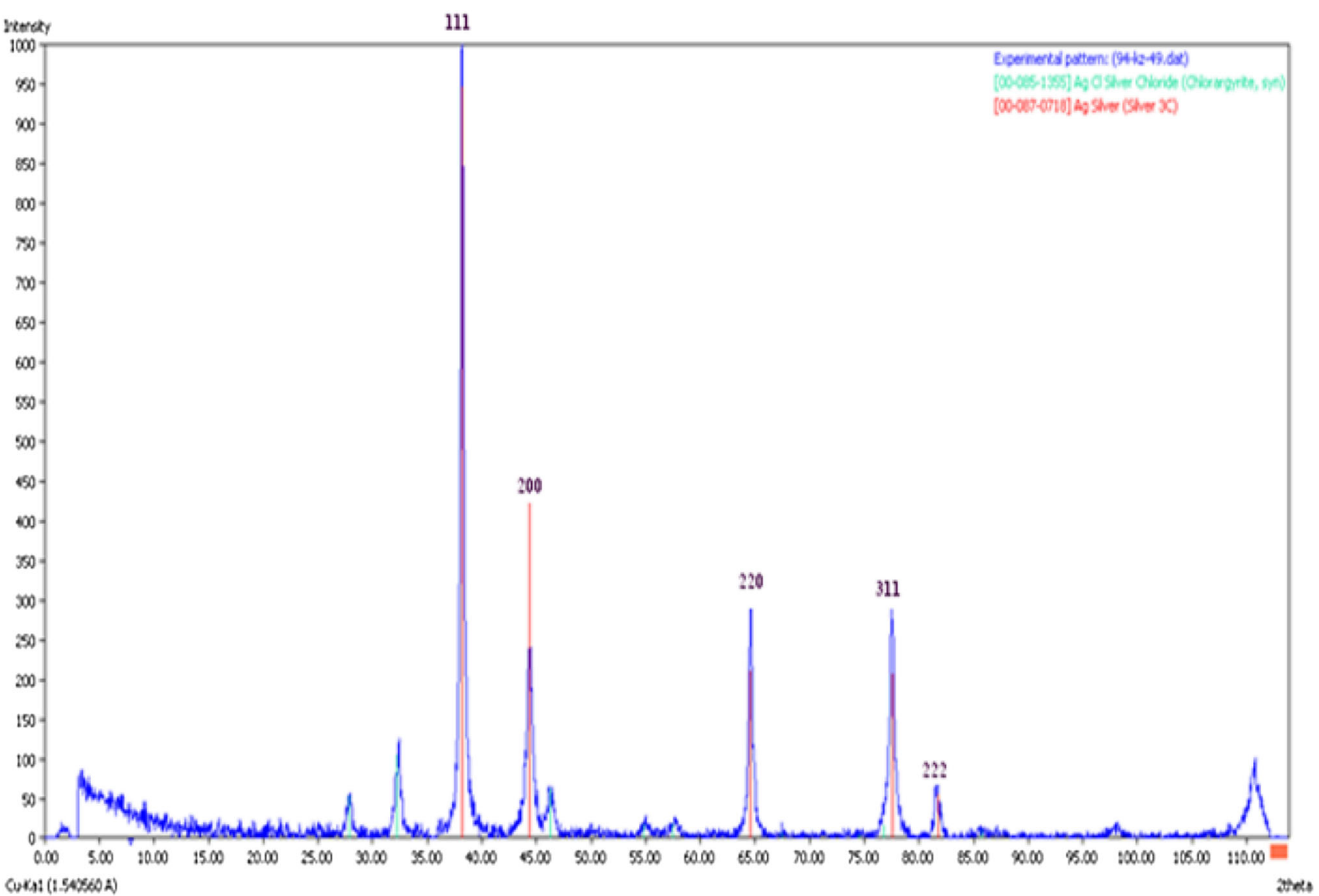

Fig. 3 X-ray diffraction spectrum of silver nanoparticles synthesized by Satureja intermedia C. A. Mey aqueous extract

\section{UV-Visible spectra analysis}

UV-Vis spectrum of SNPs showed a strong surface Plasmon resonance centered at $475 \mathrm{~nm}$ (Fig. 2) confirmed the nanocrystalline character of the particles [22]. It is generally recognized that UV-Vis spectroscopy could be used to examine size and shape-controlled nanoparticles in aqueous suspensions [23]. Silver nanoparticles have free electrons, which give rise to an SPR absorption band due to the combined vibration of electrons of metal nanoparticles in resonance with the light wave $[24,25]$.

\section{XRD analysis}

X-ray diffraction analysis was carried out to confirm the nature of nanoparticles (Fig. 3). The high intense peaks at $2 \theta$ degrees of $38.18,44.54,64.86,77.55$ and 81.54 can be attributed to the (111), (200), (220), (311) and (222) Bragg reflections, respectively, which confirm the face centered cubic (FCC) structure of SNPs. The intensity of peaks reflected the high degree of crystallinity of the silver nanoparticles. However, the diffraction peaks are broad which indicating that the crystallite size is very small.
Apart from these, there were also few other sharp peaks, which might be due to the existence of the organic phytochemicals in the mix [26]. The average size of SNPs was calculated $25.05 \mathrm{~nm}$, according to Debye-Scherrer equation: $(D=K \omega / \beta \cos \theta)$. The equation uses the reference peak width at angle $\theta$, where $\omega$ is the X-ray wavelength $(1.540560 \AA), \beta$ is the width of XRD peak at half height and $K$ is the shape factor with value 0.9 .

\section{TEM study}

A typical transmission electron microscope (TEM) image of the nanoparticles formed is presented in Fig. 4. The result showed narrow particle size distributions with diameters in range of (1.11-57.47) nm. Result was established base on 429 individual measurements. The mean diameter and standard deviation of silver nanoparticles were found $29.29 \pm 28.18(\mathrm{~nm})$.

\section{FT-IR analysis}

Fourier transform infrared spectroscopy (FT-IR), is a technique which is used to analyze the chemical 
Fig. 4 TEM images and corresponding size of SNPs synthesized by Satureja intermedia $\mathrm{C}$. A. Mey extract
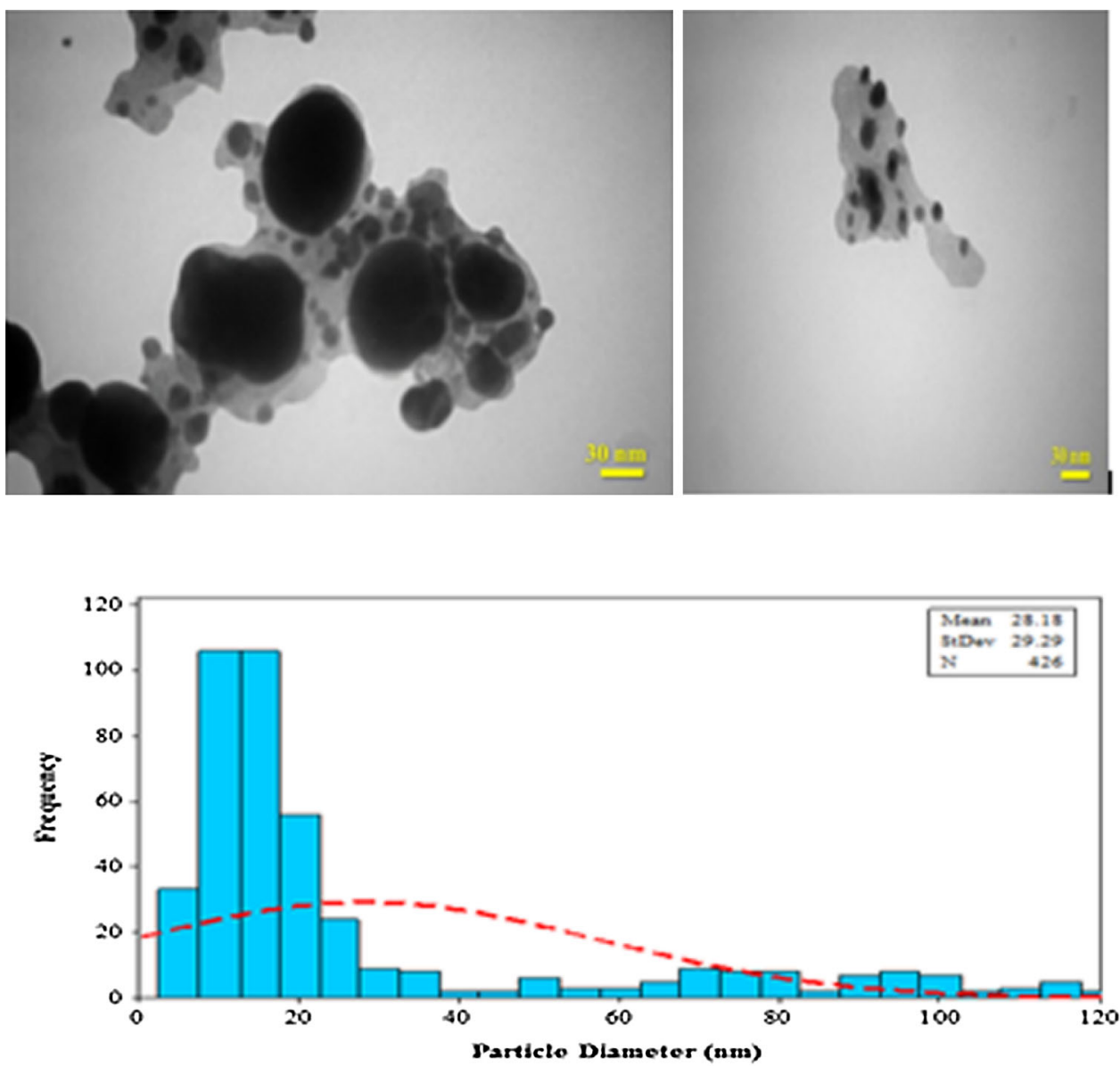

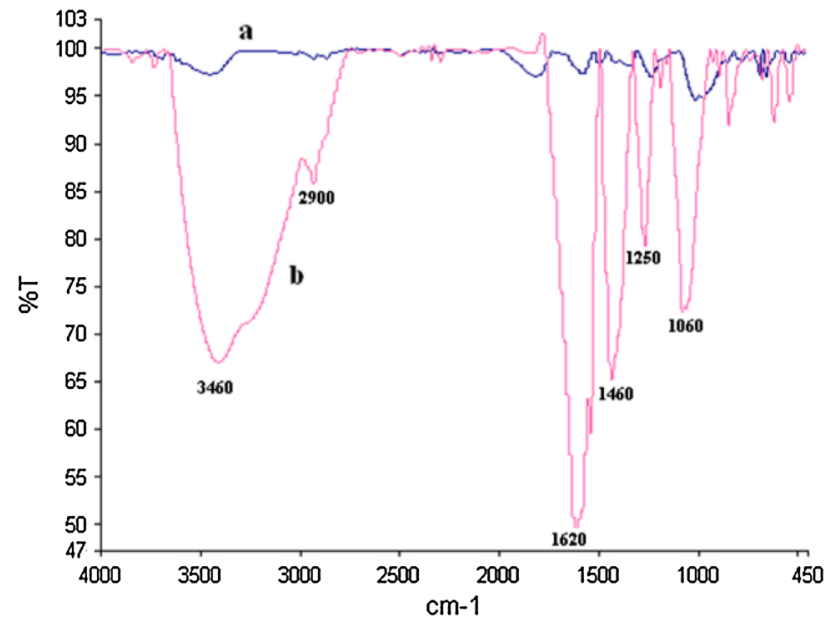

Fig. 5 FT-IR analysis of a SNPs/Satureja intermedia C.A. Mey extract mixture and b Satureja intermedia aqueous extract

composition of many organic chemicals. FT-IR spectrum of plant extract before and after synthesis of SNPs was carried out to identify the possible bio molecules responsible for the capping and stabilization of nanoparticles (Fig. 5). The broad peak at about $3400 \mathrm{~cm}^{-1}$ corresponds to stretching vibrations of $\mathrm{O}-\mathrm{H}$ bonds in alcohols, phenols

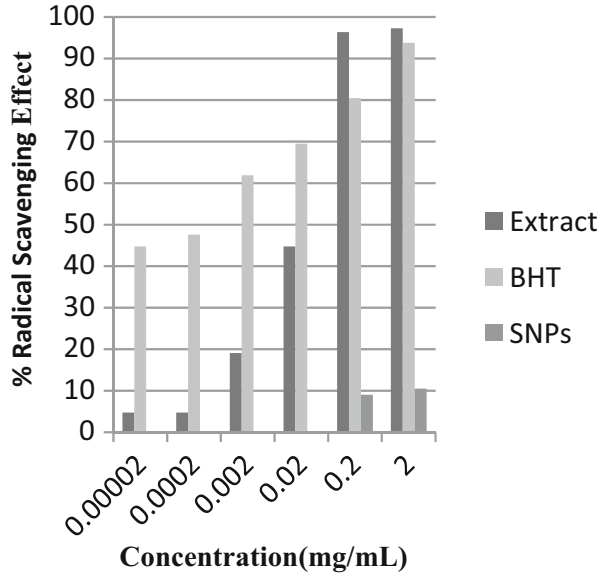

Fig. 6 Radical scavenging effect of Satureja intermedia C.A. Mey aqueous extract and synthesized Silver nanoparticles in comparison with BHT

and $\mathrm{N}-\mathrm{H}$ bond of amides. The strong band at $1620 \mathrm{~cm}^{-1}$ is attributed to the $\mathrm{C}=\mathrm{C}$ stretch in aromatic rings attributed in polyphenols and also may correspond to $\mathrm{C}=\mathrm{O}$ stretch in amides. The bonds at $1000-1300$ corresponds to $\mathrm{C}-\mathrm{C}, \mathrm{C}-\mathrm{O}$ and $\mathrm{C}-\mathrm{N}$ stretching vibrations in alcohols, phenols, esters, carboxylic acids and amides. This suggests that flavonoids, 
Phenolic compounds and proteins present in aqueous extract of the plant species could be responsible for the reduction of silver ions and for the stabilization of the phythosynthesized SNPs.

\section{DPPH scavenging assay}

Radical scavenging effect of the aqueous extract and SNPs/ extract mixture, were evaluated by DPPH scavenging assay. As shown in Fig. 6 the aqueous extract of S. intermedia exhibited higher scavenging activity in concentrations 2 and $0.2(\mu \mathrm{g} / \mathrm{mL})$ compared to SNPs/extract mixture and DPPH (as a standard). By reducing the concentration to $0.02 \mu \mathrm{g} / \mathrm{mL}$ and lower, BHT was more effective than the aqueous extract and the mixture of SNPs/extract. We can observe a correlation between the concentration of the extract and radical scavenging effect. It means that by reducing the concentration, hence reducing the level of biomolecules in the extract, the antioxidant activity will drop. Total antioxidant capacity of aqueous plant extract defines the electron supplying capacity of the extract. It could be related to SNPs formation rate, since SNPs formation relies on the reduction of $\mathrm{Ag}+$ in which the electron is supplied by the molecules in the extract.

There are many reports in the literature which shows the relation between phenolic content, antioxidant activity and potent in green synthesis of SNPs. Goodarzi et al. evaluated the antioxidant potential, total reducing capacity and SNPs synthetic potential of methanolic leaf extracts of seven plant species. They revealed that plants with high antioxidant potentials also showed higher total phenolic contents and total reducing capacity. In fact, the order of the plants reducing capacity was similar to that of their antioxidant potential [14]. Subramanian et al. demonstrated that the stem bark extract of Shorea roxburghii contain high level of total phenolic compounds and radical scavenging activity. They also revealed that the plant extract could be used as an efficient green reducing agent for the production of SNPs [27]. Ahmad et al. reported that the phenolic compounds in pineapple, exhibit excellent antioxidant activity and these phenols can react with a free radical to form the phenoxy radicals. Therefore, the use of natural antioxidants for the synthesis of SNPs seems to be a good alternative which can be due to its benign composition [28].

Although it is still under dispute, various biomolecules existing in aqueous plant extracts such as polyphenols, polysaccharides, proteins, etc. have been proposed to take role in SNPs formation [29, 30]. A majority of such biomolecules known as antioxidants $[31,32]$ are, in fact, successfully employed in the chemical synthesis of SNPs.

\section{Conclusion}

High amounts of flavonoids and phenolic compounds and a high potent of radical scavenging activity were evaluated for $S$. intermedia aqueous extract. A simple green synthesis of stable silver nanoparticles using Satureja intermedia aqueous extract was also reported in this study. These nanoparticles were synthesized with an average size of $29.29 \pm 28.18$ and spherical in shape and were characterized by XRD, TEM, UV-Visible and FT-IR spectroscopy. This eco-friendly method could be a competitive alternative to the conventional physical/chemical methods used for synthesis of silver nanoparticles. Plants with high antioxidant and reducing capacities are not only useful for the green synthesis of metallic NPs, but also for the prevention or reduction of the harmful effects of reactive oxygen species (ROS), generated during normal cellular metabolism of plants and animals.

Acknowledgments Authors are grateful to Dr. Ziba Jamzad for her help in plant collection and identification.

Open Access This article is distributed under the terms of the Creative Commons Attribution 4.0 International License (http://crea tivecommons.org/licenses/by/4.0/), which permits unrestricted use, distribution, and reproduction in any medium, provided you give appropriate credit to the original author(s) and the source, provide a link to the Creative Commons license, and indicate if changes were made.

\section{References}

1. Van Den Wildenberg, W.: Roadmap report on nanoparticles, Spain. W\&W Espana SL, Barcelona (2005)

2. Morones, J.R., Elechiguerra, J.L., Camacho, A., Holt, K., Kouri, J.B., Ramirez, J.T., Yacaman, M.J.: The bactericidal effect of silver nanoparticles. Nanotechnology. 16, 2346-2353 (2005)

3. Hang, X., Ngo, Y.W., Yu, X.: YiL.: DNA aptamer functionalized nanomaterials for intracellular analysis, cancer cell imaging and drug delivery. Ann. Mat. Pura Appl. 16, 429-435 (2012)

4. Allafchian, A.R., Mirahmadi-Zare, S.Z., Jalali, S.A.H., Hashemi, S.S., Vahabi, M.R.: Green synthesis of silver nanoparticles using phlomis leaf extract and investigation of their antibacterial activity. J. Nanostruc. Chem. 6, 129-135 (2016)

5. Pal, S., Tak, Y.K., Song, J.M.: Dose the antibacterial activity of silver nanoparticles depend on the shape of the nanoparticles? A study of the gram-negative bacterium Escherichia coli. Appl. Environ. Microbiol. 73(6), 1712-1720 (2007)

6. Becker, R.O.: Silver ions in the treatment of local infections. Met. Based Drugs 6, 297-300 (1999)

7. Ahmad, A., Mukherjee, P.S., Senapati, S., Mandal, D., Khan, M.I., Kumar, R., Sastry, M.: Extracellular biosynthesis of silver nanoparticles using the fungus Fusariumoxysporum. Colloid Surf. B. 28(4), 313-318 (2003)

8. Kaler, A., Jain, S., Banerjee, C.B.: Green and Rapid synthesis of anticancerous silver nanoparticles by Saccharomyces boulardii and insight into mechanism of nanoparticle synthesis. Biomed. Res. Int. 2013, 1-8 (2013) 
9. Jae, Y.S., Beom, S.K.: Rapid biological synthesis of Silver nanoparticles using plant Leaf extracts. Bioproc. Biosyst. Eng. 32, 79-84 (2009)

10. Mubarakali, D., Thajuddin, N., Jeqanathan, K., Gunasekaran, M.: Plant extract mediated synthesis of silver and gold nanoparticles and its antibacterial activity against clinically isolated pathogens. Colloid Surf. B. 85(2), 360-365 (2011)

11. Satyavani, K., Gurudeeban, S., Ramanathan, T., Balasubramanian, T.: Biomedical potential of silver nanoparticles synthesized from callicells of Citrulluscolocynthis. J. Nanobiotechnol. 9, 43-50 (2011)

12. Bramachari, G., Sarkar, S., Ghosh, R., Barman, S., Mandal, N.C., Jash, S.K.: Sunlight-induced rapid and efficient biogenic synthesis of silver nanoparticles using aqueous leaf extract of Ocimum sanctum Linn. with enhanced antibacterial activity. Org. Med. Chem. Lett. 4(1), 18-34 (2014)

13. Jannathul Firdhouse, M., Lalitha, P.: Biocidal potential of biosynthesized silver nanoparticles against fungal threats. J. Nanostruct. Chem. 5(1), 25-33 (2015)

14. Goodarzi, V., Zamani, H., Bajuli, L., Moradshah, A.: Evaluation of antioxidant potential and reduction capacity of some plant extracts in silver nanoparticle synthesis. Mol. Biol. Res. Commun. 3(3), 165-174 (2014)

15. Kohkonene, M.P., Hopia, A.I., Vourela, H.J., Pihlaja, K., Kujala, T.S., Heinonen, M.: Antioxidant activity of plant extract containing phenolic compounds. J. Agric. Food Chem. 47, 3954-3962 (1999)

16. Rice-evans, C.A., Miller, N.J., Bowell, P.G., Bramley, P.M., Pridham, J.B.: The relevant antioxidant activities of plant-derived polyphenolic flavonoids. Free Radic. Res. 22, 375-383 (1995)

17. Schwarz, K., Bertelsen, G., Nissen, L.R., Gardner, P.T., Heinonen, M.I., Hopia, A., Huynh-Ba, T., Lambelet, P., Mc Phail, D., Skibsted, L.H., Tijburg, L.: Investigation of plant extracts for the protection of processed foods against lipid oxidation. Comparison of antioxidant assay based on radical scavenging, lipid oxidation and analysis of the principal antioxidant compounds. Eur. Food Res. Technol. 212, 319-328 (2001)

18. Singleton, V.L., Rossi, J.A.: Colorimetry of total phenolics with phosphomolybdic-phosphotungstic acid reagents. Am. J. Enol. Viticult. 16, 144-158 (1965)

19. Chang, C.C., Yang, M.H., Wen, H.M., Chern, J.C.: Estimation of total flavonoid content in Propolis by two complementary colorimetric methods. J. Food Drug Anal. 10(3), 178-182 (2002)

20. Bondet, V., Brand-Williams, W., Berset, C.: Kinetics and mechanisms of antioxidant activity using the DPPH free radical method. LWT-Food Sci. Technol. 30, 609-615 (1997)
21. Prabha, S., Supraja, N., Garud, M., Prasad, T.N.V.K.V.: Synthesis, characterization and antimicrobial activity of Alstonia scholaris bark-extract-mediated silver nanoparticles. J. Nanostruc. Chem. 4(4), 161-170 (2014)

22. Schneider, S., Halbig, P., Grau, H., Nickel, U.: Reproducible preparation of silver sols with uniform particle size for application in surface enhanced Raman Spectroscopy. Photochem. Photobiol. 60(6), 605-610 (1994)

23. Wiley, B.J., Im, S.H., Li, Z.Y., McLellan, J., Siekkinen, A., Xia, Y.: Maneuvering the surface plasmon resonance of silver nanostructures through shape-controlled synthesis. J. Phys. Chem. 110, 15666-15675 (2006)

24. Noginov, M.A., Zhu, G., Bahoura, M., Adegoka, J., Small, C., Ritzo, B.A., Drachev, V.P., Shalaev, V.M.: The effect of gain and absorption on surface Plasmon in metal nanoparticles. Appl. Phys. B-Lasers O. 86, 455-460 (2006)

25. Dubey, M., Bhadauria, S., Kushwah, B.S.: Green synthesis of nanosilver particles from extract of Eucalyptus hybrid(Safeda) leaf. Dig. J. Nanomater. Bios. 4, 537-543 (2009)

26. Shankar, S.S., Ahmad, A., Parsricha, R., Sastry, M.: Bioreduction of chloroaurate ions by geranium leaves and its endophytic fungus yields gold nanoparticles of different shapes. J. Mater. Chem. 13, 1822-1826 (2003)

27. Subramanian, R., Subbramaniyan, P., Raj, V.: Antioxidant activity of the stem bark of Shorea roxburghii and its silver reducing power. Springer Plus 2, 28 (2013)

28. Ahmad, N., Sharma, S.: Green synthesis of silver nanoparticles using extracts of Anana comosus. Green Sustain. Chem. 2, 141-147 (2012)

29. Shan, B., Yizhong, Z., Sun, M., Corke, H.: Antioxidant capacity of 26 spice extracts and characterization of their phenolic constituents. J. Agric. Food Chem. 53, 7749-7759 (2015)

30. Szydlowska- Czerniak, A., Amarowicz, R., Szlyk, E.: Antioxidant capacity of rapeseed meal and rapeseed oils enriched with meal extract. Eur. J. Lipid Sci. Technol. 112, 750-760 (2010)

31. Martinez-Tome, M., Jimenez, A.M., Ruggieri, S., Frega, N., Strabbioli, R., Murcia, M.A.: Antioxidant properties of mediterranean spices compared with common food additives. J. Food Protect. 64, 1412-1419 (2001)

32. Li, H.B., Cheng, K.W., Wong, C.C., Fan, K.W., Chen, F., Jiang, Y.: Evaluation of antioxidant capacity and total phenolic content of different fractions of selected microalgae. Food Chem. 102, 771-776 (2001) 